\title{
Prevalence and possible causes of anemia in the elderly: a cross-sectional analysis of a large European university hospital cohort
}

\author{
Veronika Bach' \\ Guenter Schruckmayer' \\ Ines Sam' \\ Georg Kemmler ${ }^{2}$ \\ Reinhard Stauder ${ }^{\prime}$ \\ 'Department of Internal Medicine \\ $\checkmark$ (Hematology and Oncology), \\ ${ }^{2}$ Department of Biological Psychiatry, \\ Innsbruck Medical University, \\ Innsbruck, Austria
}

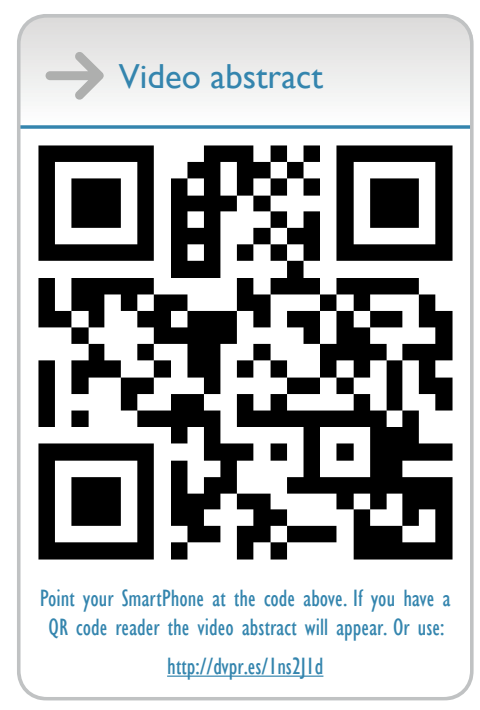

Correspondence: Reinhard Stauder Department of Internal Medicine V (Hematology and Oncology), Innsbruck Medical University, Anichstrasse 35, 6020 Innsbruck, Austria

Tel +4351250423255

Fax $+43512504256 I 5$

Email reinhard.stauder@i-med.ac.at
This article was published in the following Dove Press journal:

Clinical Interventions in Aging

22 July 2014

Number of times this article has been viewed

Background: Anemia in later life is associated with increased morbidity and mortality. The purpose of this study was to evaluate the prevalence and possible causes of anemia in the elderly in a well defined hospital cohort.

Methods: Participants in this cross-sectional, retrospective analysis included all inpatients and outpatients aged $\geq 64$ years with complete blood counts treated at Innsbruck Medical University Hospital between October 1, 2004 and September 29, 2005 ( $n=19,758$, median age 73 years).

Results: According to World Health Organization criteria, $21.1 \%$ of these patients were anemic, ie, $30.7 \%$ and $37.0 \%$ at $80+$ years and $90+$ years, respectively. The prevalence of anemia was significantly correlated with advanced age $(r=0.21 ; P<0.001)$ and male sex $(P<0.001)$. In anemic patients, renal insufficiency with a glomerular filtration rate $<30 \mathrm{~mL} / \mathrm{min} / 1.73 \mathrm{~m}^{2}$ ( $11.3 \%$ versus $2.1 \%$ ), hyperinflammation ( $62.1 \%$ versus $31.4 \%$ ), absolute $(14.4 \%$ versus $6.9 \%$ ) or functional (28.2\% versus $11.8 \%)$ iron deficiency, and folate deficiency (6.7\% versus $3.0 \%)$ were observed significantly more often than in nonanemic subjects $(P<0.001)$. The pathogenesis of anemia was multifactorial, with decreased renal function (glomerular filtration rate $<60 \mathrm{~mL} / \mathrm{min}$ / $1.73 \mathrm{~m}^{2}$ ), signs of inflammation, and functional iron deficiency detected in $11.4 \%$ of anemic patients. Hemoglobin was significantly correlated with elevated C-reactive protein $(r=-0.296$; $P<0.001)$ and low transferrin saturation $(r=0.313 ; P<0.001)$. Mean corpuscular volume correlated only weakly with the various anemia subtypes. Cytopenias and morphologic alterations suggestive of underlying myelodysplastic syndromes were found in a substantial proportion of anemic patients, including thrombocytopenia (5.4\%), leukopenia (8.26\%), and macrocytic alterations (18.4\%).

Conclusion: Anemia was frequently diagnosed in this series of elderly patients. Partly treatable nutritional deficiencies, such as iron or folate deficiency, were identified as possible causes. A complex and heterogeneous interplay of chronic inflammation, functional iron deficiency, and renal impairment was identified in a large proportion of patients. A hitherto undiagnosed myelodysplastic syndrome can be assumed in a relevant proportion of patients. Morphologic classification based on mean corpuscular volume is inadequate from the standpoint of pathogenesis. New parameters are needed to differentiate the multifactorial pathogenesis of anemia in the elderly.

Keywords: anemia, elderly, prevalence, causes, myelodysplastic syndromes

\section{Introduction}

Anemia is frequently detected in the elderly and poses a major clinical burden. The prevalence of anemia ranges from $12 \%$ in the community, to $40 \%$ in patients admitted to hospital, to $47 \%$ in nursing home residents, giving a mean prevalence of $17 \%{ }^{1}$ The prevalence of anemia increases dramatically with advancing age, reaching nearly $50 \%$ in elderly men, ${ }^{2,3}$ and will increase further due to population aging. ${ }^{1}$ Anemia is 
associated with increased morbidity and mortality, ${ }^{4,5}$ and can lead to cardiovascular and neurological events. ${ }^{6}$ Correlations have been shown between anemia and limited physical performance, ${ }^{7,8}$ impairment in ability to perform activities of daily living, ${ }^{9}$ weakness, fatigue, and frailty, ${ }^{10}$ falls and fractures, ${ }^{10,11}$ frequency and duration of hospital stays, ${ }^{5,6}$ cognitive impairment, ${ }^{7}$ depression, ${ }^{9,10}$ and dementia. ${ }^{11}$

Despite the clinical relevance of anemia in the elderly, the underlying causes are not well understood. A large proportion is due to chronic inflammation or renal impairment. ${ }^{3,11}$ Additionally, malnutrition may lead to vitamin $\mathrm{B}_{12}$, folate, or iron deficiency, resulting in anemia. ${ }^{12}$ Moreover, anemia might be an early sign of a previously undiagnosed malignant disorder, including the myelodysplastic syndromes (MDS). ${ }^{13}$ MDS are associated with advanced age and are often characterized by anemia without alterations in white cell count or platelets. ${ }^{14}$ Finally, unexplained anemia, where no specific cause can be identified, is present in one third of the anemic elderly. ${ }^{3}$

The aim of this study was to analyze potential anemiarelated factors in a large well defined cohort of elderly persons to investigate the prevalence and possible causes of anemia. These data are intended to form an evidence base for individualized treatment approaches.

\section{Materials and methods Data collection}

Demographic data and laboratory values of all patients aged $\geq 64$ years treated at Innsbruck Medical University Hospital, Austria between October 1, 2004 and September 29, 2005 were analyzed. Local ethics committee approval was obtained. Laboratory values were assessed during routine workup and treatment of patients. The first blood count available was used for evaluation. All analyses were performed at the Central Institute for Medical and Chemical Laboratory Diagnostics (ZIMCL) of Innsbruck Medical University Hospital. ZIMCL holds the Quality Austria Certificate for all analyses performed in this study (http://www. qualityaustria.com/).

\section{Definition of anemia and nutritional deficiencies}

Reference values were taken from ZIMCL or from the published literature as indicated. Anemia was defined as hemoglobin $<12 \mathrm{~g} / \mathrm{dL}$ in women and $<13 \mathrm{~g} / \mathrm{dL}$ in men, in accordance with World Health Organization (WHO) criteria. ${ }^{15}$ Absolute iron deficiency was defined as a serum ferritin $<30 \mathrm{ng} / \mathrm{mL}$.
Functional iron deficiency was subcategorized as mild or moderate based on transferrin saturation $<16 \%$ and serum ferritin $>100 \mathrm{ng} / \mathrm{mL}$ or serum ferritin $30-100 \mathrm{ng} / \mathrm{mL}$, respectively (reference values taken from Ludwig et al ${ }^{16}$ Aapro et al, ${ }^{17}$ and ZIMCL). Moreover, anemia was classified as microcytic ( $<77 \mathrm{fl})$, normocytic (77-96 fl), or macrocytic ( $>96 \mathrm{fl}$ ) according to mean corpuscular volume based on data from the literature and ZIMCL reference values. ${ }^{18}$ Definitions of anemia subtypes are presented in Table 1.

\section{Study population}

Patient records were available for 43,210 patients aged $\geq 64$ years. Full blood counts were available for 19,758 of these patients, and were included in the analysis. More than $98 \%$ of the study population was of Caucasian origin. Patients were recruited from all units and outpatient clinics of Innsbruck Medical University, the main contributors being the emergency unit of the department of internal medicine $(n=2,157$, $11 \%$ ), emergency admissions to the department of neurology $(n=917,4.6 \%)$, department of cardiology $(n=895,4.5 \%)$, and surgical outpatient clinic $(n=869,4.4 \%)$. Three percent of the patients came from the hematology outpatient clinic, $2.7 \%$ from the rheumatology outpatient clinic, $2.7 \%$ from the general outpatient clinic, and $2.6 \%$ from cardiology ward. The remaining patients came from numerous other wards and outpatient clinics $(n=212)$ at Innsbruck Medical University Hospital. Details on patient selection and the analyses performed in the study cohort are shown in Figure 1.

\section{Statistical methods}

Data were retrieved from the electronic hospital database (Cerner Millennium, Idstein, Germany). A plausibility check of all data was conducted upon database entry and critical missing or implausible data were clarified.

Summary statistics (mean and standard deviation, median, and range) were used for the description of continuous variables. The number and percentage of participants in each category were reported for categorical variables. For comparison of two groups with respect to continuous variables, the Mann-Whitney $U$ test was used, given that most of the respective variables were not normally distributed. Fisher's exact test was applied for comparison of two groups with regard to binary categorical variables. Logistic regression analyses were performed to analyze the impact of gender, age, renal insufficiency, inflammation, absolute or functional iron deficiency, folate deficiency, vitamin $\mathrm{B}_{12}$ deficiency, leukopenia, and thrombopenia on the prevalence of anemia. 
Table I Classification of anemia based on laboratory parameters

\begin{tabular}{|c|c|c|c|c|c|c|}
\hline \multirow[t]{2}{*}{ Parameter } & \multicolumn{2}{|l|}{ Overall } & \multicolumn{2}{|l|}{ Nonanemic } & \multicolumn{2}{|l|}{ Anemic } \\
\hline & $n / \mathbf{N}$ & $\%$ & $n / \mathbf{N}$ & $\%$ & $n / \mathbf{N}$ & $\%$ \\
\hline Total & 19,758 & 100 & $|5,58| / \mid 9,758$ & 79.0 & $4,1 / 7 / 19,758$ & 21.1 \\
\hline \multicolumn{7}{|l|}{ Renal insufficiency } \\
\hline $\mathrm{GFR}^{*}<60 \mathrm{~mL} / \mathrm{min} / \mathrm{l} .73 \mathrm{~m}^{2}$ & $5,906 /|8,27|$ & 32.3 & $4,185 / 14,459$ & 28.9 & $1,721 / 3,812$ & 45.1 \\
\hline $\mathrm{GFR}^{*}<30 \mathrm{~mL} / \mathrm{min} / 1.73 \mathrm{~m}^{2}$ & $728 /|8,27|$ & 4.0 & $297 / 14,459$ & 2.1 & $431 / 3,8 \mid 2$ & 11.3 \\
\hline Inflammation (CRP $>0.7 \mathrm{mg} / \mathrm{dL})$ & $6,47|/| 6,882$ & 38.3 & $4,101 / 13,067$ & 31.4 & $2,370 / 3,815$ & 62.1 \\
\hline Absolute iron deficiency $(\mathrm{SF}<30 \mathrm{ng} / \mathrm{mL}$ ) & $360 / 3,826$ & 9.4 & $193 / 2,668$ & 7.2 & $167 / 1,158$ & 14.4 \\
\hline \multicolumn{7}{|l|}{ Functional iron deficiency } \\
\hline TSAT $<16 \%$, SF $30-100$ ng/mL & $219 / 3,715$ & 5.9 & $98 / 2,581$ & 3.8 & $121 / 1,134$ & 10.7 \\
\hline TSAT $<16 \%$, SF $>100 \mathrm{ng} / \mathrm{mL}$ & $405 / 3,715$ & 10.9 & $206 / 2,581$ & 8.0 & $199 / 1,134$ & 17.5 \\
\hline Folate deficiency $(<3.8 \mathrm{ng} / \mathrm{mL})$ & $138 / 3,363$ & 4.1 & $68 / 2,290$ & 3.0 & $70 / 1,042$ & 6.7 \\
\hline Vitamin $B_{12}$ deficiency $(<|4|$ pmol/L) & $51 / 3,302$ & 1.5 & $31 / 2,298$ & $1.3^{\#}$ & $20 / 1,004$ & $2.0^{\#}$ \\
\hline \multicolumn{7}{|l|}{ Cytopenias } \\
\hline Thrombopenia (<100 G/L) & $373 / 19,758$ & 1.9 & $|45 /| 5,58 \mid$ & 0.9 & $228 / 4,177$ & 5.5 \\
\hline Leukopenia $(<4 \mathrm{G} / \mathrm{L})$ & $882 / 19,758$ & 4.2 & $477 / 15,581$ & 3.1 & $345 / 4,177$ & 8.3 \\
\hline Leukopenia (<2 G/L) & $54 / 19,758$ & 0.3 & $9 / 15,581$ & 0.1 & $45 / 4,177$ & 1.1 \\
\hline \multicolumn{7}{|l|}{ Multifactorial anemia } \\
\hline $\mathrm{GFR}^{*}<60 \mathrm{~mL} / \mathrm{min} / \mathrm{l} .73 \mathrm{~m}^{2}+\mathrm{CRP}>0.7 \mathrm{mg} / \mathrm{dL}$ & $2,4 \mid 7 / 15,995$ & 15.1 & $\mathrm{I}, 4|7 /| 2,440$ & 11.4 & $\mathrm{I}, 000 / 3,555$ & 28. 1 \\
\hline $\mathrm{GFR}^{*}<30 \mathrm{~mL} / \mathrm{min} / 1.73 \mathrm{~m}^{2}+\mathrm{CRP}>0.7 \mathrm{mg} / \mathrm{dL}$ & $469 / 15,995$ & 2.9 & $172 / 12,440$ & 1.4 & $297 / 3,555$ & 8.4 \\
\hline $\mathrm{GFR}^{*}<60 \mathrm{~mL} / \mathrm{min} / \mathrm{l} .73 \mathrm{~m}^{2}+\mathrm{CRP}>0.7 \mathrm{mg} / \mathrm{dL}+\mathrm{FID}$ & $220 / 3,575$ & 6.2 & $94 / 2,468$ & 3.8 & $126 / 1,107$ & 11.4 \\
\hline $\mathrm{GFR}^{*}<30 \mathrm{~mL} / \mathrm{min} / \mathrm{I} .73 \mathrm{~m}^{2}+\mathrm{CRP}>0.7 \mathrm{mg} / \mathrm{dL}+\mathrm{FID}$ & $59 / 3,575$ & 1.7 & $15 / 2,468$ & 0.6 & $44 / 1,107$ & 4.0 \\
\hline $\mathrm{CRP}>0.7 \mathrm{mg} / \mathrm{dL}+\mathrm{FID}$ & $462 / 3,585$ & 12.9 & $214 / 2,475$ & 8.6 & $248 / 1,110$ & 22.3 \\
\hline
\end{tabular}

Notes: Leukopenias as defined by Common Terminology Criteria for Adverse Events. $P$-values for anemic versus nonanemic: $P=0.170$; all others $P<0.00$ I. (FID: TSAT $<16 \%, \mathrm{SF} \geq 30 \mathrm{ng} / \mathrm{mL})$. *According to the Modification of Diet Renal Disease study. ${ }^{45}$

Abbreviations: CRP, C-reactive protein; GFR, glomerular filtration rate; n, number positive; N, number evaluated; SF, serum ferritin; TSAT, transferrin saturation; FID, functional iron deficiency.

Associations between hemoglobin and other parameters were evaluated using Spearman rank-correlation coefficients.

The chi-squared test was used to analyze the relationship between mean corpuscular volume and various laboratory parameters. All statistical tests were conducted at a 0.05 level of significance. Statistical analyses were performed using the Statistical Package for the Social Sciences version 20.0 software (IBM Corporation, New York, NY, USA).

\section{Results}

\section{Patient characteristics and demographics}

The median age was 73 (range 64-104) years (75 years in women and 72 years in men; $P<0.001$, Table 2 ). A relevant proportion of patients had impaired renal function and signs of inflammation. Nutritional deficiencies, including folate and vitamin $B_{12}$, were rare. An absolute or relative iron deficiency was observed in one quarter of the patients.

\section{Prevalence of anemia}

Median hemoglobin was $13.7 \mathrm{~g} / \mathrm{dL}$. Women generally had lower hemoglobin levels than did men (median $13.4 \mathrm{~g} / \mathrm{dL}$ versus $14.3 \mathrm{~g} / \mathrm{dL} ; P<0.001)$. A gender difference was found across all age groups $(P<0.001$ for all but the oldest age group $[P=0.010])$. According to WHO criteria, $21.1 \%$ of the patients were anemic, ${ }^{15}$ with a higher prevalence seen in men than in women overall (23.4\% versus 19.3\%) and across all age groups $(P<0.001)$. The prevalence of anemia increased significantly with advancing age $(P<0.001)$, reaching a prevalence of $30.7 \%$ and $37.0 \%$ at $\geq 80$ years and $\geq 90$ years, respectively. Severe anemia (defined as hemoglobin $<10 \mathrm{~g} / \mathrm{dL}$ ) was found in $3.7 \%$ of patients (3\% men, $4 \%$ women), with a significantly higher prevalence in the elderly (nearly $8 \%$ in patients $\geq 90$ years; $P<0.001$ ). Overall, hemoglobin levels were significantly lower in patients of advanced age, as shown by correlation analysis $(r=-0.21 ; P<0.001$, see Tables 2 and 3 ).

\section{Possible causes of anemia}

Signs of renal impairment, hyperinflammation, and relevant nutrient deficiencies were evaluated. In general, deviations from reference values were observed more frequently in anemic than in nonanemic patients for all parameters $(P<0.001)$ except vitamin $\mathrm{B}_{12}(P=0.170)$.

Mild-to-moderate renal impairment was detected in $45.1 \%$ of anemic patients and was more frequent in women than in men $(41.0 \%$ versus $49.3 \% ; P<0.001)$. Severe renal 


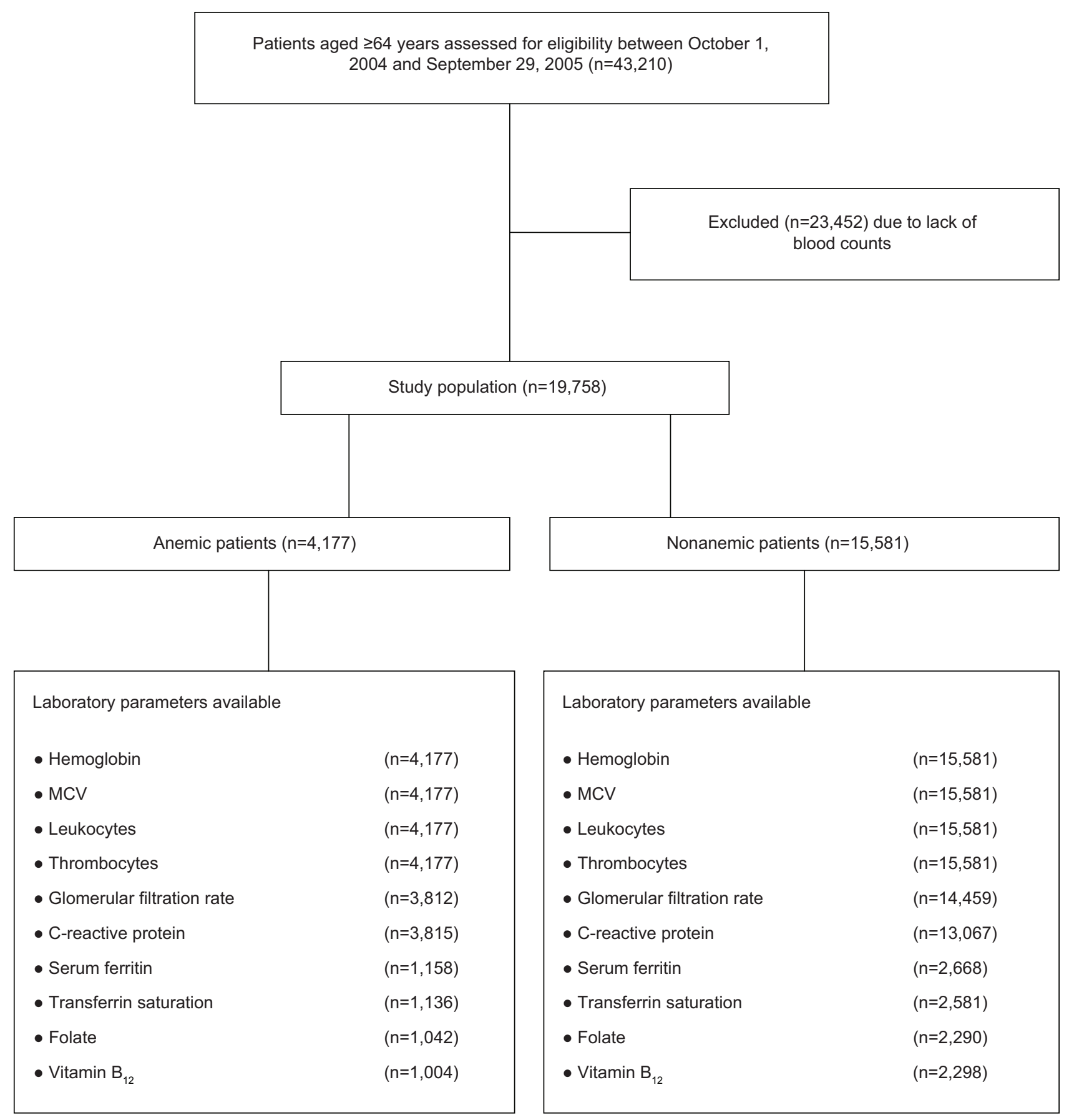

Figure I Overview of patient selection and laboratory analyses.

Abbreviation: MCV, mean corpuscular volume.

insufficiency was detected in $11.3 \%$ of anemic patients. Glomerular filtration rate (GFR) correlated weakly with hemoglobin levels $(r=0.139 ; P<0.001)$.

C-reactive protein was measured to detect anemia of chronic inflammation (ACI). Elevated C-reactive protein levels were significantly more prevalent in anemic than in nonanemic patients. C-reactive protein was inversely correlated with hemoglobin levels $(r=-0.296 ; P<0.001)$.
Absolute iron deficiency was documented in $14.4 \%$ and functional iron deficiency in $28.2 \%$ of anemic patients, with a female preponderance (absolute iron deficiency $11.5 \%$ in males versus $17.3 \%$ in females, $P=0.005$; functional iron deficiency $24.2 \%$ in males versus $32.2 \%$ in females, $P=0.003$ ). Low transferrin saturation was significantly correlated with low hemoglobin $(r=0.313 ; P<0.001)$. Folate and vitamin $\mathrm{B}_{12}$ deficiency was rare $(6.7 \%$ and $2.0 \%$, respectively). 
Table 2 Patient demographics and characteristics

\begin{tabular}{|c|c|c|}
\hline Parameter & $\mathbf{n} / \mathbf{N}$ & Result \\
\hline Male, \% (n) & 19,758 & $44.7(8,84 I)$ \\
\hline Inpatients, \% (n) & 19,758 & $45.7(9,021)$ \\
\hline \multirow[t]{2}{*}{ Age, mean (median) $\pm S D$, years } & & $74.3(73) \pm 7.4$ \\
\hline & & Range 64-104 \\
\hline $\mathrm{Hb}$, mean (median) $\pm \mathrm{SD}, \mathrm{g} / \mathrm{dL}$ & 19,758 & $13.6(13.7) \pm 1.8$ \\
\hline Glomerular filtration rate*, mean (median) $\pm S D, \mathrm{~mL} / \mathrm{min} / 1.73 \mathrm{~m}^{2}$ & 18,217 & $68.9(69) \pm 22.4$ \\
\hline C-reactive protein, mean (median) $\pm \mathrm{SD}, \mathrm{mg} / \mathrm{dL}$ & 16,882 & $2.44(0.58) \pm 4.9$ \\
\hline Serum ferritin, mean (median) $\pm S D, n g / m L$ & 3,826 & $277.2(137) \pm 743.7$ \\
\hline Transferrin saturation, mean (median) $\pm \mathrm{SD}, \%$ & 3,717 & $26.6(24) \pm 15.3$ \\
\hline Folate, mean (median) $\pm \mathrm{SD}, \mathrm{ng} / \mathrm{mL}$ & 3,363 & $8.0(7.4) \pm 3.2$ \\
\hline Vitamin $B_{12}$, mean (median) $\pm S D$, pmol/L & 3,302 & $505(4 \mid 5.5) \pm 323.6$ \\
\hline Thrombocytes, mean (median) $\pm \mathrm{SD}, \mathrm{G} / \mathrm{L}$ & 19,758 & $239(228) \pm 84$ \\
\hline Leukocytes, mean (median) $\pm \mathrm{SD}, \mathrm{G} / \mathrm{L}$ & 19,758 & $7.6(6.8) \pm 5.2$ \\
\hline
\end{tabular}

Notes: *According to the Modification of Diet Renal Disease study ${ }^{45}$

Abbreviations: $n$, number positive; $\mathrm{N}$, number evaluated; SD, standard deviation; Hb, hemoglobin.

Multifactorial anemia was observed frequently. In 28.1\% of anemic patients with mild-to-moderate renal insufficiency, increased inflammation markers were observed. Similarly, a considerable proportion of patients with severe renal insufficiency had elevated C-reactive protein levels. Signs of inflammation and functional iron deficiency were associated with a GFR $<60 \mathrm{~mL} / \mathrm{min} / 1.73 \mathrm{~m}^{2}$ in $11.4 \%$ of anemic patients and with a GFR $<30 \mathrm{~mL} / \mathrm{min} / 1.73 \mathrm{~m}^{2}$ in $4.0 \%$.

Logistic regression analysis was performed to test for the joint effect of renal insufficiency (GFR $<60$ : OR (odds ratio) 1.73 [1.35-2.22, 95\% CI]; GFR <30: OR 6.57 [4.31-10.03]), inflammation (OR 2.53 [2.00-3.19]), absolute (OR 2.86, [2.01-4.08]) and functional iron deficiency (OR 2.47 [1.863.27]), folate deficiency (OR 1.37 [0.83-2.28]), vitamin $B_{12}$ deficiency (OR 1.08 [0.46-2.52]), leukopenia ( $<4$ G/L: OR 3.96 [2.49-6.30]; <2 G/L: OR 10.50 [2.61-42.21]), and thrombocytopenia (OR 4.19, [2.56-6.88]) on the prevalence of anemia, with adjustment for age and sex. The analysis revealed that all variables tested, except for folate $(P=0.217)$ and vitamin $\mathrm{B}_{12}(P=0.860)$, were independently associated with a higher risk for anemia $(P<0.001)$.
Outpatients were characterized by more favorable laboratory values than were inpatients, with the former found to be anemic less often $(13.8 \%$ versus $29.9 \% ; P<0.001)$. Accordingly, outpatients showed higher values for hemoglobin, transferrin saturation, and folate, and lower levels for serum ferritin and C-reactive protein $(P<0.001)$.

\section{Mean corpuscular volume-based anemia classification}

Normocytic anemia was the most frequent subtype (78.0\%) along with microcytic (3.7\%) and macrocytic (18.4\%). In general, microcytic and normocytic anemia were more frequently seen in women than in men $(58.2 \%, P=0.004$, and $52.5 \%, P<0.001$, respectively), whereas macrocytic anemia showed a male preponderance $(60 \%, P<0.001)$. Absolute iron deficiency was more commonly microcytic $(P<0.001)$, whereas functional iron deficiency was predominantly normocytic. Similarly, ACI was mostly normocytic in nature $(P=0.02)$. Folate deficiency was predominant in macrocytic anemia $(P=0.08)$. Thrombopenia and leukopenia

Table 3 Age distribution of anemia

\begin{tabular}{|c|c|c|c|c|}
\hline $\begin{array}{l}\text { Age groups, } \\
\text { years }\end{array}$ & $\begin{array}{l}\text { Age distribution } \\
\%(n)\end{array}$ & $\begin{array}{l}\text { Hb values }(\mathrm{g} / \mathrm{dL}) \\
\text { Mean } \pm \mathrm{SD}\end{array}$ & $\begin{array}{l}\text { Prevalence } \\
\text { of anemia } \% \text { (n) }\end{array}$ & 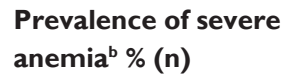 \\
\hline Total & $100(19,758)$ & $13.6 \pm 1.8$ & 2 I.I $(4,177)$ & 3.7 (722) \\
\hline $64-69$ & $31.8(6,290)$ & $13.9 \pm 1.7$ & I5.I (949) & $2.5(155)$ \\
\hline 70-74 & $23.1(4,573)$ & $13.8 \pm 1.8\}^{* * *}$ & $18.3(835)$ & $3.0(135)$ \\
\hline $75-79$ & $20.5(4,056)$ & $13.5 \pm 1.8\}$ & $22.3(903)\} * *$ & $3.6(148)$ \\
\hline $80-84$ & $14.9(2,943)$ & $13.1 \pm 1.8\}^{* * *}$ & $28.4(837)\} * *$ & $5.0(148)\}^{\} *}$ \\
\hline $85-89$ & $5.8(1,155)$ & $12.9 \pm 1.8\}^{* *}$ & $32.8(379)\} *$ & $6.6(76)\}^{*}$ \\
\hline$\geq 90$ & $3.9(74 I)$ & $12.7 \pm 2.0\}^{*}$ & $37.0(274)$ & $8.1(60)$ \\
\hline
\end{tabular}

Notes: $\mathrm{a} \mathrm{Hb}<12 \mathrm{~g} / \mathrm{dL}$ in women and $<13 \mathrm{~g} / \mathrm{dL}$ in men; ${ }^{b} \mathrm{Hb}<10 \mathrm{~g} / \mathrm{dL}$. $P$-values for differences between age groups: $* P<0.05$; $* P<0.001$.

Abbreviations: $\mathrm{Hb}$, hemoglobin; $\mathrm{n}$, number positive; $\mathrm{SD}$, standard deviation. 
Table 4 Distribution of MCV subtypes as compared with the different causes of anemia

\begin{tabular}{|c|c|c|c|c|c|c|}
\hline \multirow[t]{2}{*}{ Parameter } & \multicolumn{2}{|c|}{ Microcytic } & \multicolumn{2}{|c|}{ Normocytic } & \multicolumn{2}{|c|}{ Macrocytic } \\
\hline & $\mathbf{n} / \mathbf{N}$ & $\%$ & $\mathbf{n} / \mathbf{N}$ & $\%$ & $\mathbf{n} / \mathbf{N}$ & $\%$ \\
\hline Total & $153 / 4,177$ & 3.7 & $3,257 / 4,177$ & 78.0 & $767 / 4,177$ & 18.4 \\
\hline \multicolumn{7}{|l|}{ Renal insufficiency } \\
\hline $\mathrm{GFR}^{\mathrm{a}}<60 \mathrm{~mL} / \mathrm{min} / \mathrm{l} .73 \mathrm{~m}^{2}$ & $6 I / I, 72 I$ & 3.5 & $|, 3| 3 / I, 72 \mid$ & 76.3 & $347 / I, 721$ & 20.2 \\
\hline $\mathrm{GFR}^{\mathrm{a}}<30 \mathrm{~mL} / \mathrm{min} / \mathrm{l} .73 \mathrm{~m}^{2}$ & $|6 / 43|$ & 3.7 & $324 / 431$ & 75.2 & $91 / 431$ & 21.1 \\
\hline Inflammation (CRP >0.7 mg/dL) & $62 / 2,370$ & 2.6 & $\mathrm{I}, 907 / 2,370$ & $80.5^{*}$ & $40 \mathrm{I} / 2,370$ & 16.9 \\
\hline Absolute iron deficiency (SF $<30 \mathrm{ng} / \mathrm{mL}$ ) & $45 / 167$ & $26.9 * *$ & $115 / 167$ & 68.9 & $7 / 167$ & 4.2 \\
\hline \multicolumn{7}{|l|}{ Functional iron deficiency } \\
\hline TSAT $<16 \%$, SF $>100$ ng/mL & $|2 /| 2 \mid$ & $10.0^{*}$ & $97 / 121$ & 80.1 & $|2 /| 2 \mid$ & 10.0 \\
\hline TSAT $<16 \%$, SF $30-100 \mathrm{ng} / \mathrm{mL}$ & $4 / 199$ & 2.0 & $164 / 199$ & 82.4 & $31 / 199$ & 15.6 \\
\hline Folate deficiency $(<3.8 \mathrm{ng} / \mathrm{mL})$ & $3 / 70$ & 4.3 & $48 / 70$ & 68.6 & $19 / 70$ & $27 . I^{\#}$ \\
\hline Vitamin $B_{12}$ deficiency $(<141 \mathrm{pmol} / \mathrm{L})$ & $4 / 20$ & $20.0^{*}$ & $7 / 20$ & 35.0 & $9 / 20$ & $45.0^{*}$ \\
\hline \multicolumn{7}{|l|}{ Cytopenias } \\
\hline Thrombopenia (<100 G/L) & $5 / 228$ & 2.2 & $143 / 228$ & 62.7 & $80 / 228$ & $35.1 * *$ \\
\hline Leukopenia $(<4 \mathrm{G} / \mathrm{L})$ & $7 / 345$ & 2.0 & $224 / 345$ & 64.9 & II4/345 & $33.1^{* *}$ \\
\hline Leukopenia (<2 G/L) & $1 / 45$ & 2.3 & $29 / 45$ & 64.4 & $15 / 45$ & $33.3^{*}$ \\
\hline
\end{tabular}

Notes: Leukopenias as defined by Common Terminology Criteria for Adverse Events. $P$-values: $* P<0.05 ; * * P<0.001$; ${ }^{*} P=0.08$; all others not significant. aAccording to the Modification of Diet Renal Disease study. ${ }^{45}$

Abbreviations: CRP, C-reactive protein; GFR, glomerular filtration rate; n, number positive; N, number evaluated; SF, serum ferritin; TSAT, transferrin saturation; MCV, mean corpuscular volume.

were observed significantly more often in macrocytic anemia $(P<0.001$, Table 4).

\section{Anemia as a possible early sign of MDS}

Signs suggestive of an underlying MDS were investigated. Thrombopenia or leukopenia was significantly more frequent in macrocytic anemia than in microcytic or normocytic anemia (Table 4) and was detected as a possible sign of MDS in a relevant group of anemic patients $(5.5 \%$ and $8.3 \%$, respectively). The large proportion of patients with macrocytic anemia (16.4\%) could not be explained by vitamin $B_{12}$ or folate deficiency (Figure 2).

\section{Discussion}

We analyzed a large, well characterized hospital cohort of elderly inpatients and outpatients for prevalence of anemia

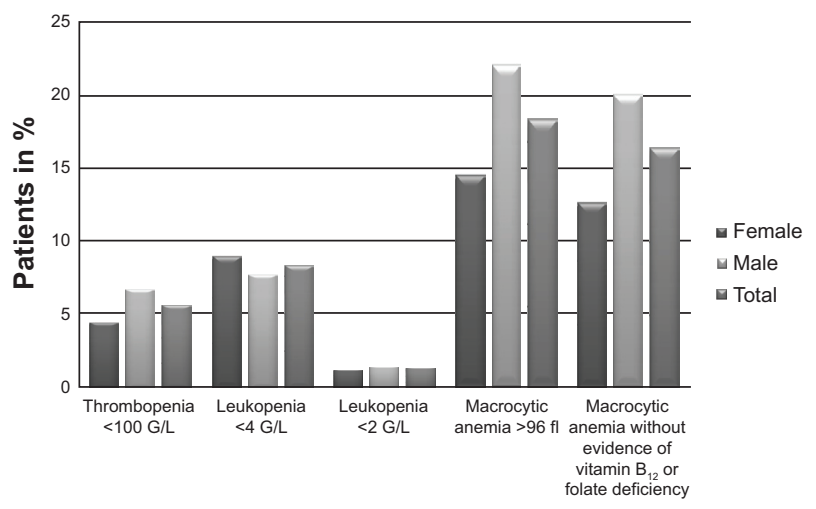

Figure 2 Evidence for possible underlying myelodysplastic syndromes in anemic patients $(n=4,177)$. and potential causes and risk factors, including occult MDS. This study is relevant because of its large patient number of nearly 20,000 patients, including many very elderly patients (741 aged $\geq 90$ years). To date, the prevalence of anemia in patients from this age group has only been studied by Tettamanti et $\mathrm{al}^{2}$ who investigated 427 patients $\geq 90$ years, and by Haslam et al ${ }^{19}$ who studied 244 patients $\geq 98$ years.

In the current study, the prevalence of anemia was $21.1 \%$. Further differentiation revealed a higher prevalence in men than in women and an age-dependent increase. Overall, the prevalence and differences according to gender and age are consistent with those reported in other studies. ${ }^{1,10,20}$ A systematic review of 34 studies found a prevalence of anemia of $17 \%$ (range 3\%-50\%), ${ }^{1}$ while another showed an age-dependent prevalence of $2.9 \%-61 \%$ in men and $3.3 \%-41 \%$ in women. ${ }^{10}$ An age dependency of anemia was also found in a longitudinal Swedish study. ${ }^{20}$ The high prevalence of anemia in the elderly warrants routine assessment and appropriate treatment. ${ }^{21}$

In this study, the prevalence of severe anemia (hemoglobin $<10 \mathrm{~g} / \mathrm{dL}$ ) was $3 \%$ in men and $4 \%$ in women, reaching nearly $8 \%$ in patients aged $\geq 90$ years, irrespective of gender. Tettamanti et al ${ }^{2}$ found $10.3 \%$ of anemic patients were $\geq 90$ years in an Italian cohort. Identification of severe anemia in this age group is essential because of increased morbidity and mortality ${ }^{4,5,9}$ and decreased cognitive and functional capacities. ${ }^{7,9}$ Its predictive value for mortality in the very old was recently confirmed. ${ }^{22}$

In keeping with previous studies, ${ }^{1}$ our study showed a higher anemia prevalence of $29.9 \%$ in patients admitted to 
hospital as compared with $13.8 \%$ in outpatients. Direct comparison with other hospital-based data is difficult, because most of the data available in the literature are derived from community-dwelling residents from a university hospital anemia clinic, in whom a selection bias can be assumed because of their referral to a specialized outpatient clinic. ${ }^{23}$ Other studies are based on geriatric patients ${ }^{24,25}$ or on an Indian population, characterized by a different social and ethnic background. ${ }^{26}$ In general, the findings reported in the literature ${ }^{3,8,27,28}$ and the findings from our study reveal a higher prevalence in hospital-based cohorts than in communitydwelling persons.

The definition of anemia in the elderly in the literature is controversial. The WHO criteria were established in the 1960 s in a cohort lacking individuals $>65$ years,${ }^{29}$ thus permitting their general applicability in the elderly to be questioned. Alternative definitions are established using a threshold of less than the mean minus two standard deviations $^{30}$ or by relying on definitions by percentiles. ${ }^{22}$ The challenge of this approach, however, is how to define and recruit appropriate reference populations. Exclusion of more than $60 \%$ of patients from reference cohorts on the basis of comorbidities $^{30}$ introduces a massive bias and clearly limits the relevance of these borderline values. Given that the literature contains no generally accepted definition of anemia in the elderly, the WHO definition was used in this study because it is used in the majority of studies published. ${ }^{1,10}$

The National Health and Nutrition Examination Survey III classifies anemia into four categories by underlying cause, ie, anemia from nutrient deficiencies, renal anemia, ACI and, in the absence of other identifiable causes, unexplained anemia. ${ }^{3}$ Recent studies have shown that anemia from nutrient deficiencies, renal anemia and/or ACI, and unexplained anemia, are each responsible for one third of anemic patients. ${ }^{3,23}$ The listed categories, however, are not mutually exclusive and several pathologies may coexist in an individual patient.

The current study indicates a large proportion of anemia cases associated with renal impairment and chronic inflammation. Nutritional deficiencies account for a smaller but potentially treatable proportion. Renal anemia is associated with reduced renal production of erythropoietin, ${ }^{31}$ which is commonly treated with erythropoiesis-stimulating factors. ${ }^{32}$ In this study, $45.1 \%$ of anemic patients had a GFR $<60 \mathrm{~mL} / \mathrm{min} /$ $1.73 \mathrm{~m}^{2}$ and $11.3 \%$ had a GFR $<30 \mathrm{~mL} / \mathrm{min} / 1.73 \mathrm{~m}^{2}$. This prevalence is in accordance with that in the National Health and Nutrition Examination Survey III, ${ }^{3}$ with $12.5 \%$ of anemic patients having renal insufficiency, while Shavelle et $\mathrm{al}^{33}$ reported a figure of $11 \%$. The GFR threshold below which renal anemia is considered to be present remains controversial. A GFR threshold $<30 \mathrm{~mL} / \mathrm{min} / 1.73 \mathrm{~m}^{2}$ was defined by Ble et $\mathrm{al}^{27}$ and Artz and Thirman ${ }^{23}$ whereas Cumming et $\mathrm{al}^{28}$ reported a relevant decrease in hemoglobin at GFR $<50 \mathrm{~mL} / \mathrm{min} / 1.73 \mathrm{~m}^{2}$. Our study found a $29.1 \%$ prevalence of anemia at a GFR of $<60 \mathrm{~mL} / \mathrm{min} / 1.73 \mathrm{~m}^{2}$ and $60 \%$ at $<30 \mathrm{~mL} / \mathrm{min} / 1.73 \mathrm{~m}^{2}$, as well as a weak correlation between GFR and anemia. These findings suggest that renal insufficiency contributes to anemia in the elderly at even moderate GFR reductions.

$\mathrm{ACI}$ is primarily related to hyperinflammation involving C-reactive protein and the interleukin-6/hepcidin axis. ACI is thought to cause functional iron deficiency via a complex interplay of inflammatory cytokines and their effects on erythropoietin production and iron metabolism. ${ }^{34-36}$ Diagnosis can include use of markers such as hepcidin, erythropoietin, soluble transferrin receptor, or the soluble transferrin receptor/log ferritin ratio. ${ }^{35}$ However, in practice, it is often diagnosed by exclusion or use of elevated $\mathrm{C}$-reactive protein as a surrogate. In this study, ACI as defined by elevated $\mathrm{C}$-reactive protein, was considered in $62.1 \%$ of anemic patients. Semba et $\mathrm{al}^{37}$ found ACI in $22 \%-45 \%$ and Shavelle et $\mathrm{al}^{33}$ in $26 \%$ of anemia patients. Elevated C-reactive protein was significantly more frequent in anemic than in nonanemic patients and C-reactive protein was inversely correlated with hemoglobin $(r=-0.296 ; P<0.001)$, supporting the inflammation-anemia axis. We believe our reliance on C-reactive protein alone as a surrogate might have overestimated the prevalence of ACI, since some patients with modestly increased C-reactive protein may not actually have had ACI. However, our findings are supported by the high prevalence of functional iron deficiency (28\%) and simultaneously increased C-reactive protein levels in patients with functional iron deficiency (nearly $80 \%$ ), both of which are caused by a similar mechanism. However, new assays for analyzing the hepcidin-ferroportin axis might improve the diagnosis and differentiation of ACI. ${ }^{36}$

Absolute iron deficiency was observed in $14.4 \%$ of our anemic cases. Two previous studies showed a $16 \%$ prevalence of iron deficiency anemia. ${ }^{2,3}$ Iron deficiency anemia is relevant in the elderly because blood loss, inadequate iron intake, and as yet undiagnosed tumors should be excluded. ${ }^{12}$ Patients with iron deficiency anemia can be effectively treated with oral or intravenous iron substitution. Effective and well tolerated intravenous iron compounds have been developed recently. Low serum ferritin levels reliably indicate a depletion of iron stores. Normal serum ferritin 
in the elderly, however, does not completely rule out iron deficiency, as serum ferritin increases with age and in inflammatory processes. ${ }^{35}$

Functional iron deficiency is based on inadequate iron delivery to the bone marrow in the presence of normal or mildly decreased iron storage. Several markers and cutoffs have been proposed and used for monitoring of iron status and diagnosis of functional iron deficiency. ${ }^{16,17,35}$ Functional iron deficiency is differentiated from absolute iron deficiency by low transferrin saturation, an indicator of iron supply. Diagnostic criteria, however, vary between studies. We defined two subcategories of functional iron deficiency as transferrin saturation $<16 \%$ and serum ferritin $>100 \mathrm{ng} / \mathrm{mL}$ (mild) or serum ferritin 30-100 ng/mL (moderate). In this study, functional iron deficiency was taken into account in one quarter of anemic patients. Low hemoglobin levels were significantly correlated with low transferrin saturation $(r=0.313$; $P<0.001$ ), supporting the role of functional iron deficiency in the pathogenesis of anemia. In many studies, functional iron deficiency is listed under unexplained anemia. If diagnosis of iron deficiency is based solely on serum ferritin $<30 \mathrm{ng} / \mathrm{mL}$, it often goes undiagnosed, as Ludwig et $\mathrm{al}^{16}$ have pointed out. Assessing iron status in anemic patients therefore needs to include transferrin saturation, but this is rarely done. ${ }^{2,23}$

In our study, low vitamin $\mathrm{B}_{12}$ was found in $2 \%$ of anemic patients, which is in line with other studies. ${ }^{38}$ However, nonanemic patients show vitamin $\mathrm{B}_{12}$ deficiency to a similar degree, thus supporting the observations of a lack of correlation between vitamin $\mathrm{B}_{12}$ levels and anemia reported by den Elzen et al. ${ }^{39}$ Folate deficiency was identified in $6.7 \%$ of our anemic patients. Recent studies found folate deficiency in $6.4 \%-9.3 \%$ of patients $^{3,16}$ and also showed an association with anemia in patients aged $\geq 85$ years. ${ }^{39}$ Concomitant measurement of homocysteine and methylmalonyl co-enzyme A might enhance the sensitivity and specificity of detecting vitamin $B_{12}$ or folate deficiencies. ${ }^{40}$

Mean corpuscular volume is used for morphologic classification of anemia. ${ }^{18}$ Normocytic anemia was the most common type of anemia observed, confirming previous studies. ${ }^{20}$ Microcytic anemia was detected in a minor proportion of patients and was significantly associated with absolute iron deficiency. ACI and functional iron deficiency were more frequent in normocytic than in microcytic or macrocytic anemia. Folate and vitamin $B_{12}$ deficiency were more frequent in macrocytic anemia (not significant). These results suggest that, except for the correlation between microcytic anemia and iron deficiency, mean corpuscular volume-based classification of anemia is not reliable and does not mirror the underlying pathogenesis.
The association between anemia and MDS was investigated, as MDS often underlies unexplained anemia. ${ }^{23}$ Patients with MDS often have macrocytosis in the absence of folate or vitamin $B_{12}$ deficiency, occasionally accompanied by neutropenia or thrombocytopenia. ${ }^{41}$ Macrocytic anemia without evidence of vitamin $\mathrm{B}_{12}$ or folate deficiency was observed in $16.4 \%$ of our anemia cases, a decrease in platelets in $5.4 \%$, a moderate $(<4 \mathrm{G} / \mathrm{L})$ leukopenia in $8 \%$, and severe $(<2 \mathrm{G} / \mathrm{L})$ leukopenia in $1 \%$. Thus, occult MDS might account for about $10 \%$ of cases of anemia. This number is plausible given that MDS was reported to be diagnosed in $5 \%{ }^{24}$ to $15 \%{ }^{14}$ of anemic or cytopenic geriatric patients. The incidence and prevalence of MDS are particularly high in the elderly, reaching a prevalence of 50/100,000 in persons aged $\geq 80$ years. ${ }^{42} \mathrm{~A}$ bone marrow examination should be considered in unclear macrocytic anemia, especially if additional cytopenias are observed, other possible causes of a leukopenia or thrombocytopenia have been excluded, or the patient presents with a history of prior chemotherapy or radiation therapy. ${ }^{43}$ New molecular and flow cytometry techniques detecting clonal hematopoiesis will further clarify the role of MDS in unexplained anemia. Pilot studies have enabled diagnosis of MDS from peripheral blood without evaluating bone marrow. ${ }^{44}$ Exact MDS diagnosis is essential, because effective and well tolerated treatments are available for the elderly. ${ }^{41}$

The present study has some limitations. Analyses were performed retrospectively on the basis of a single set of laboratory values, rather than repeated measurements and clinical evaluations. Thus, it cannot be said with certainty whether abnormal laboratory parameters were caused by a chronic or an acute condition. Identification of the cause of anemia was also impossible, because of the complexity of the data and the retrospective study design. Thus, prospective studies are needed to investigate the causes and pathogenetic mechanisms of anemia, as are prospective studies regarding its impact on functional capacity, frailty, and mortality in the elderly. Another limitation of this study is its hospital-based design. For this reason, our findings are restricted to hospital patients and cannot be translated to the general population. Moreover, our cohort was a population of predominantly Caucasian origin $(>98 \%)$. Given that ethnic differences in the prevalence of anemia are well known, 3,7 comparisons with other studies should take into account the ethnic background of the relevant population. Further, the laboratory values for the nutrition-related parameters (iron, vitamin $\mathrm{B}_{12}$, and folate) were determined in only $18 \%$ of the study cohort. Although performance of these analyses in only part of the patient population could be viewed as a selection bias, the large number of analyses performed $(>3,000)$ and 
the accordance of our findings with those in the literature should be taken into consideration and argue for the validity of our findings. ${ }^{2,3,27}$

Our study underscores the relevance of anemia in the elderly and contributes to the understanding of its possible causes. Future studies on parameters such as hepcidin, erythropoietin, reticulocyte hemoglobin content, and soluble transferrin receptor will help us to understand better and differentiate the multifactorial pathogenesis of anemia. This will enable individualized treatments based on substitution of iron, folic acid, vitamin $\mathrm{B}_{12}$, erythropoiesis-stimulating factors, and agents targeting the hepcidin-ferroportin axis or hyperinflammation. ${ }^{36}$

\section{Author contributions}

Concept and design: VB, GK, and RS. Acquisition of subjects and/or data: VB, GS, IS, and RS. Analysis and interpretation of data: VB, GS, IS, GK, and RS. Preparation of manuscript: VB, GS, IS, GK, and RS. All authors took part in drafting the article or revising it critically for important intellectual content.

\section{Acknowledgments}

This work was supported by VereinSenioren-Krebshilfe (RS, AH). Margit Hemetsberger of Hemetsberger Medical Services, Vienna, Austria, helped with the editing of the manuscript. Mary Heaney Margreiter edited and proofread the manuscript.

\section{Disclosure}

The authors report no conflicts of interest in this work.

\section{References}

1. Gaskell H, Derry S, Andrew Moore R, McQuay HJ. Prevalence of anaemia in older persons: systematic review. BMC Geriatr. 2008;8:1.

2. Tettamanti M, Lucca U, Gandini F, et al. Prevalence, incidence and types of mild anemia in the elderly: the "Health and Anemia" population-based study. Haematologica. 2010;95(11):1849-1156.

3. Guralnik JM, Eisenstaedt RS, Ferrucci L, Klen HG, Woodman RC. Prevalence of anemia in persons 65 years and older in the United States: evidence for a high rate of unexplained anemia. Blood. 2004;104(8): 2263-2268.

4. Izaks GJ, Westendorp RG, Knook DL. The definition of anemia in older persons. JAMA. 1999;281(18):1714-1717.

5. Penninx BW, Pahor M, Woodman RC, Guralnik JM. Anemia in old age is associated with increased mortality and hospitalization. $J$ Gerontol $A$ Biol Sci Med Sci. 2006;61(5):474-479.

6. Culleton BF, Manns BJ, Zhang J, Tonelli M, Klarenbach S, Hemmelgarn BR. Impact of anemia on hospitalization and mortality in older adults. Blood. 2006;107(10):3841-3856.

7. Denny SD, Kuchibhatla MN, Cohen HJ. Impact of anemia on mortality, cognition, and function in community-dwelling elderly. Am J Med. 2006;119(4):327-334.
8. Penninx BW, Pahor M, Cesari M, et al. Anemia is associated with disability and decreased physical performance and muscle strength in the elderly. J Am Geriatr Soc. 2004;52(5):719-724.

9. den Elzen WP, Willems JM, Westendorp RG, de Craen AJ, Assendelft WJ, Gussekloo J. Effect of anemia and comorbidity on functional status and mortality in old age: results from the Leiden 85-Plus study. CMAJ. 2009;181(3-4):151-157.

10. Beghe C, Wilson A, Ershler WB. Prevalence and outcomes of anemia in geriatrics: a systematic review of the literature. Am J Med. 2004;116 Suppl 7A:3S-10S.

11. Balducci L. Anemia, fatigue and aging. Transfus Biol. 2010;17(5-6): 375-381.

12. Carmel R. Nutritional anemias and the elderly. Semin Hematol. 2008;45(4):225-334.

13. Edgren G, Bagnardi V, Bellocco R, et al. Pattern of declining hemoglobin concentration before cancer diagnosis. Int J Cancer. 2010;127(6): 1429-1436.

14. Beloosesky Y, Cohen AM, Grosman B, Grinblat J. Prevalence and survival of myelodysplastic syndrome of the refractory anemia type in hospitalized cognitively different geriatric patients. Gerontology. 2000; 46(6):323-327.

15. World Health Organization. Haemoglobin concentrations for the diagnosis of anaemia and assessment of severity. Geneva, Switzerland: World Health Organization; 2011. Available from: http://www.who. int/vmnis/indicators/haemoglobin.pdf. Accessed May 5, 2014.

16. Ludwig H, Müldür E, Endler G, Hübl W. Prevalence of iron deficiency across different tumors and its association with poor performance status, disease status and anemia. Ann Oncol. 2013;24(7):1886-1892.

17. Aapro M, Osterborg A, Gascon P, et al. Prevalence and management of cancer-related anaemia, iron deficiency and the specific role of i.v. iron. Ann Oncol. 2012;23(8):1954-1962.

18. Brugnara C, Mohandas N. Red cell indices in classification and treatment of anemias: from M.M. Wintrobes's original 1934 classification to the third millennium. Curr Opin Hematol. 2013;20(3): 222-223.

19. Haslam A, Hausman DB, Davey A, Elaine Cress M, Johnson MA, Poon LW. Associations of anemia and physical function in Georgia centenarians. J Am Geriatr Soc. 2012;60(12):2362-2363.

20. Nilsson-Ehle H, Jagenburg R, Landahl S, Svanborg A, Westin J. Decline of blood haemoglobin in the aged: a longitudinal study of an urban Swedish population from age 70 to 81 . Br J Haematol. 1989;71(3): $437-442$.

21. Hammer A, Göbel G, Anliker M, et al. Feasibility and accuracy of non-invasive anemia screening. J Am Geriatr Soc. 2014;62(1): 199-201.

22. van Houwelingen AH, den Elzen WP, Mooijaart SP, et al. Predictive value of a profile of routine blood measurements on mortality in older persons in the general population: the Leiden 85-Plus study. PLoS One. 2013;8(3):e58050.

23. Artz AS, Thirman MJ. Unexplained anemia predominates despite an intensive evaluation in a racially diverse cohort of older adults from a referral anemia clinic. J Gerontol A Biol Sci Med Sci. 2011;66(8): 925-932.

24. Joosten E, Pelemans W, Hiele M, et al. Prevalence and causes of anaemia in a geriatric hospitalized population. Gerontology. 1992;38(1-2): 111-117.

25. Dharmarajan TS, Avula S, Norkus EP. Anemia increases risk for falls in hospitalized older adults: an evaluation of falls in 362 hospitalized, ambulatory, long-term care, and community patients. J Am Med Dir Assoc. 2007;8(3 Suppl 2):e9-e15.

26. Veena Nandigam N, Nandigam K, Badhe BA, Dutta TK. Is adult definition of anemia applicable to a geriatric population? Study of erythrocyte parameters in Indian geriatric inpatients. J Am Geriatr Soc. 2004;52(9): 1589-1590.

27. Ble A, Fink JC, Woodman RC, et al. Renal function, erythropoietin, and anemia of older persons: the InCHIANTI study. Arch Intern Med. 2005;165(19):2222-2227. 
28. Cumming RG, Mitchell P, Craig JC, Knight JF. Renal impairment and anaemia in a population-based study of older people. Intern Med J. 2004;34(1-2):20-23.

29. Blanc B, Finch CA, Hallberg L, et al. Nutritional anaemias. Report of a WHO scientific group. World Health Organ Tech Rep Ser. 1968; 405:5-37.

30. Beutler E, Waalen J. The definition of anemia: what is the lower limit of normal of the blood hemoglobin concentration? Blood. 2006;107(5): 1747-1750.

31. Artunc F, Risler T. Serum erythropoietin concentrations and responses to anaemia in patients with or without chronic kidney disease. Nephrol Dial Transplant. 2007;22(10):2900-2908.

32. Kidney Disease Improving Global Outcomes. KDIGO Clinical Practice Guideline for anemia in chronic kidney disease. Kidney Int. 2012; Suppl 2:279-335.

33. Shavelle RM, MacKenzie R, Paculdo DR. Anemia and mortality in older persons: does the type of anemia affect survival? Int J Hematol. 2012;95(3):248-256.

34. Ferrucci L, Guralnik JM, Woodman RC, et al. Proinflammatory state and circulating erythropoietin in persons with and without anemia. Am J Med. 2005;118(11):1288.

35. Weiss G, Goodnough LT. Anemia of chronic disease. $N$ Engl J Med. 2005;352(10):1011-1023.

36. Sun CC, Vaja V, Babitt JL, Lin HY. Targeting the hepcidin-ferroportin axis to develop new treatment strategies for anemia of chronic disease and anemia of inflammation. Am J Hematol. 2012;87(4): $392-400$.
37. Semba RD, Guralnik JM, Chaves P, et al. Iron status and anemia in a population-based study of women with and without disability living in the community: the Women's Health and Aging Studies. Haematologica. 2004;89(3):357-358.

38. Loikas S, Koskinen P, Irjala K, et al. Vitamin B12 deficiency in the aged: a population-based study. Age Ageing. 2007;36(2):177-183.

39. den Elzen WP, Westendorp RG, Frolich M, et al. Vitamin B12 and folate and the risk of anemia in old age: the Leiden 85-Plus study. Arch Intern Med. 2008;168(20):2238-2244.

40. Aslinia F, Mazza JJ, Yale SH. Megaloblastic anemia and other causes of macrocytosis. Clin Med Res. 2006;4(3):236-241.

41. Malcovati L, Hellstrom-Lindberg E, Bowen D, et al. Diagnosis and treatment of primary myelodysplastic syndromes in adults: recommendations from the European LeukemiaNet. Blood. 2013;122(17):2943-2964.

42. Neukirchen J, Schoonen WM, Strupp C, et al. Incidence and prevalence of myelodysplastic syndromes: data from the Dusseldorf MDS-registry. Leuk Res. 2011;35(12):1591-1596.

43. Merchant AA, Roy CN. Not so benign haematology: anaemia of the elderly. Br J Haematol. 2012;156(2):173-185.

44. Braulke F, Jung K, Schanz J, et al. Molecular cytogenetic monitoring from CD34+ peripheral blood cells in myelodysplastic syndromes: first results from a prospective multicenter German diagnostic study. Leuk Res. 2013;37(8):900-906.

45. Levey AS, Bosch JP, Lewis JB, Greene T, Rogers N, Roth D. A more accurate method to estimate glomerular filtration rate from serum creatinine: a new prediction equation. Modification of Diet in Renal Disease Study Group. Ann Intern Med. 1999;130(6):461-470.
Clinical Interventions in Aging

\section{Publish your work in this journal}

Clinical Interventions in Aging is an international, peer-reviewed journal focusing on evidence-based reports on the value or lack thereof of treatments intended to prevent or delay the onset of maladaptive correlates of aging in human beings. This journal is indexed on PubMed Central, MedLine,

\section{Dovepress}

CAS, Scopus and the Elsevier Bibliographic databases. The manuscript management system is completely online and includes a very quick and fair peer-review system, which is all easy to use. Visit http://www.dovepress. com/testimonials.php to read real quotes from published authors. 